\title{
Eğitim müfettişlerinin tercih ettikleri denetim stillerinin kontrol odağına göre karşılaş̦tırılması
}

\author{
Canan ÇETINKANAT* \\ Mesut SAĞNAK**
}

Öz

$\mathrm{Bu}$ araştırmanın amac1, eğitim müfettişlerinin denetim stillerine ilişkin tercihlerini kontrol odağına göre karşılaştırmaktır. Araştırmaya 472 eğitim müfettişi ve müfettiş yardımcısı katılmıştır. Araştırmada iki farklı ölçme aracı kullanılmıştır. Eğitim müfettişlerinin denetim tercihlerini belirlemek için denetim inançları envanteri, denetim odağını belirlemek için İç-Dış Kontrol Odağı Ölçeği kullanılmıştır. Eğitim müfettişlerinin denetim stillerine ilişkin tercihlerinin sırasıyla yönlendirici olmayan denetim, işbirlikli denetim ve yönlendirici denetim olduğu sonucuna ulaşılmıştır. Kontrol odağına göre eğitim müfettişlerinin yönlendirici ve yönlendirici olmayan denetim stillerine ilişkin tercihleri arasında anlamlı fark bulunmuştur. Dış kontrol odaklı eğitim müfettişlerinin yönlendirici denetim stilini, iç kontrol odaklı eğitim müfettişlerinin ise yönlendirici olmayan denetim stilini daha çok tercih ettikleri belirlenmiştir. Kontrol odağına göre eğitim müfettişlerinin işbirlikli denetim stiline ilişkin tercihleri arasında anlamlı fark bulunmamıştır.

Anahtar kelimeler: Denetim, denetim stilleri, eğitim müfettişi, kontrol odağı

\section{A comparison of supervisory styles preferred by educational supervisors according to locus of control}

\begin{abstract}
The purpose of this study was to compare supervisory styles preferred by educational supervisors according to Locus of Control. The sample of this study includes 472 supervisors and deputy supervisors. Two different inventories were used for this research. Supervisory Beliefs Inventory was used to determine supervisory styles preferred by educational supervisors and InternalExternal Locus of Control Scale was used to determine supervisors' locus of control. The findings show that educational supervisors preferred respectively nondirective supervision, collaborative
\end{abstract}

* Prof.Dr., Lefke Avrupa Üniversitesi, Dr. Fazık Küçük Eğitim Fakültesi, cteninkanat@eul.edu

* $\quad$ Doç.Dr., Niğde Üniversitesi, Eğitim Fakültesi, mesutsagnak@hotmail.com 
supervision and directive supervision styles. According to internal-external locus of control, there is a statistically significant difference between nondirective and directive supervisory styles. While external control oriented supervisors preferred directive supervision style, internal control oriented supervisors preferred nondirective supervisory style. Based upon the scores on the internal-external locus of control scale, the findings show that there is no significant difference in terms of the preferred collaborative supervision styles.

Keywords: Supervision, supervision styles, educational supervisors, locus of control

\section{Giriş}

İçinde bulunduğumuz çağın en önemli özelliği değişimin çok hızlı yaşanmasıdır. Dinamik bir çevre karşısında yöneticilerin görevi örgütün çevreye uyum yeteneğini geliştirmek ve etkili olarak hayatını devam etmesini sağlamaktır. Örgütsel davranış alanında son yıllarda yapılan çalışmalar, katılımcı yönetim, çalışanların güçlendirilmesi, yetki ve sorumluluklarının artırılması, önemli ve anlamlı bir işte çalıştığı inancının geliştirilmesi gibi çalışanlara odaklı ve onları daha aktif hale getirmeyi amaçlayan öneriler geliştirmiştir. Başka bir açıdan ifade edilecek olursa, örgütlerde adalet algısına ilişkin olumlu bir iklimin oluşturulması yoluyla örgütsel vatandaşlık ve bağlllık davranışlarının geliştirilmesi ve bu iklim içerisinde çalışanların potansiyellerini kullanabilecekleri ve risk alabilecekleri bir serbestliğin sağlanmasıyla etkililiğin elde edilebileceği ileri sürülmektedir. $\mathrm{Bu}$ nedenle örgütte çalışan insanların tüm yönleriyle tanınması özellikle kişilik özelliklerinin bilinmesi, onların desteklenmesi ve potansiyellerini kullanabilmeleri açısından önemlidir.

Örgütte çalı̧an insanların kişilik özelliklerinin başında 'kontrol odağı' kavramının geldiği söylenebilir (Robbins, 1986). Kontrol odağı kavramı, sosyal öğrenme yaklaşımına dayalı olarak geliştirilmiştir (Spector, 1982). İç-dış kontrol odağı, bir kişinin davranış-pekiştireç olasılıkları ile ilgili beklentilerini genelleştirmesi olarak tanımlanır. Sosyal öğrenme yaklaşımına göre, iç kontrollü kişiler, pekiştireçleri kontrol etme yeteneğine sahip olduklarına inanırken, dış kontrollü kişiler pekiştireçleri başka güçler, şans gibi faktörlerin belirlediğine inanır (Autry ve Langenbach, 1985; Goodstadt ve Hjelle, 1973).

Kontrol odağı, psikolojide ve diğer sosyal bilimlerde en çok araştırılan değişkenlerden biridir (Rotter, 1990). Örgütsel ortamlarda ise, kontrol odağının çalışanların işe karşı tutumlarını ve örgütsel niteliklere ilişkin algılarını nasıl etkilediğini belirlemeye yönelik birçok araştırma yapılmıştır (Cheng, 1994; Martin, Thomas, Charles, Epitropaki ve McNamara, 2005). Bu araştırmalarda, kontrol odağının doyum, bağlılık, motivasyon, performans, etkililik, verimlilik, başarı, stres, bireysel yenilik, duygusal zeka gibi değişkenlerle ilişkisi belirlenmeye çalışılmıştır (Anderson, Hattie ve Hamilton, 2005; Anderson ve Schneier, 1978; Ashkanasy, 1991; Blau, 1993; Chen ve Silverthorne, 2008; Cheng, 1994; Deniz, Traş ve Aydoğan, 2009 Johnson, Luthans ve Hennessey, 1984; Kirkcaldy, Shephard ve Furnham, 2002; Klein ve Wasserstein-Warnet, 2000; Martin vd., 2005; Parkay, Greenwood, Olejnik ve Proller, 1988; Türker ve İnel, 2012). Bu 
araştırmaların sonuçlarına göre, iç kontrollü çalşsanların dış kontrollü çalışanlara göre doyum, bağlılık, motivasyon, performans, etkililik, verimlilik, duygusal zeka, yenilik, başarı düzeylerinin daha yüksek ve stres düzeylerinin daha düşük olduğu genel olarak söylenebilir.

Örgütlerde kontrol odağı ile ilgili araştırmaların önemli bir kısmı, bir kişilik boyutu olarak görülen kontrol odağının (Durand ve Nord, 1976; Nystrom, 1982) liderlik stillerine ve izleyenlerin bu stillere ilişkin algılarını belirlemeye yönelik olmuştur. Goodstadt ve Hjelle (1973), bir denetimsel rol ortamında, dış kontrollü kişilerin daha çok zorlayıcı gücü kullandıklarını, içsellerin teşvik etme, ödül, öğüt ve yeni standartlar belirleme gibi daha çok kişisel ikna gücünü kullandıklarını belirlemiştir. Mitchell, Smyser ve Weed (1975), içsellerin katılımcı yönetim stilinden, dışsalların ise yönlendirici stilden daha çok doyum elde ettiklerini, içsellerin astları etkilemede en etkili yollar olarak ödül, uzmanlık ve saygıyı, dışsalların ise formal pozisyonlarını ve zorlayıcı gücü en etkili yollar olarak gördüklerini bulmuştur. Araştırmacılar bu bulgulara dayalı olarak, içsellerin yönetimde daha çok zorlayıcı olmayan bir tarzda davranacaklarını ileri sürmüştür. Rucker ve King (1985), üniversite öğrencileri üzerinde yaptığı araştırmada, içsellerin katılım olanaklarından etkilendiğini, dışsalların yönlendirmeyi tercih ettiğini belirtmiş̧ir. Biondo ve MacDonald (1971) dışsalların taleplere ve tepkilere duyarlı olduğunu, etkiye karşı uyum davranışı sergilediğini, içsellerin ise etkiye karşı direnç gösterdiğini saptamıştır.

Johnson, Luthans ve Hennessey (1984), liderlik sürecinde kontrol odağı ile ilgili araştırmaların daha çok astlar üzerinde yapıldığını ileri sürerek, kontrol odağının liderin davranışlarını nasıl etkilediğini belirlemeye çalışmışlardır. Araştırmacılar, iç kontrollü denetçilerin dış kontrollü denetçilere göre daha çok ikna yolunu kullanma eğiliminde olduklarını belirlemiştir. Bu araştırma, kontrol odağının denetçilerin davranışlarının önemli bir kestirici olduğunu belirlemiş, içsel denetçilerin astları etkilemede daha çok kişisel gücü, dışsal denetçilerin ise kurumsal gücü tercih ettiğini saptamıştır (Askanasy, 1991). Araştırmalarda ulaşılan sonuçlar genelleştirildiğinde, içsellerin, çevresini kontrol etme girişiminde bulunduğu, başarıya daha çok motive olduğu, karar vermeden önce bilgi topladığı, işlerinde daha başarıll, girişimi ve bağımsız eylemleri gerektiren işlere daha uygun oldukları ileri sürülebilir. Bununla birlikte dışsalların, yönlendirmeleri kabul etmede daha istekli ve uyumlu davrandığı, yapılandırılmış ve rutin işleri daha iyi yaptığı söylenebilir (Robbins, 1986).

Glickman (1990), denetçi-öğretmen ilişkisini açıklayan ve kontrolün derecesine göre yapılandırdığı yönlendirici, işbirlikli ve yönlendirici olmayan olarak isimlendirdiği üç tür denetim stili ileri sürmüş ve şu şekilde açıklamıştır: Yönlendirici denetim, öğretimin teknik beceriler ile belirli standartlardan oluştuğu ve öğretmenlerin etkili olabilmesi için belirli yeterliklere sahip olması gerektiği inancına dayalı bir yaklaşımdır. Denetçilerin rolü, bilgi verme, yönlendirme, model olma ve yeterlikleri değerlendirmedir. Bu yaklaşım, denetçinin öğretmenden daha çok bilgi ve tecrübeye sahip olduğu varsayımına dayanır. Başka bir deyişle, yönlendirici kontrol davranışları, öğretimin geliştirilebilmesi için neyin yapılması gerektiğini denetçinin öğretmenden daha iyi bildiği inancına dayanır. Bu yaklaşımda denetçi, herhangi bir öğretim problemini üstlenir. Gözlemleri yoluyla elde ettiği bilgilere dayalı olarak problemi tanımlar. Öğretmene ne yapması gerektiğini söyler ve uygulanması gereken önerilerinin nedenlerini açılar. Önerilen eylemi 
yeniden gözden geçirir ve öğretmenden beklentilerini tekrarlayarak süreci bitirir. Öğretmen kendisinden beklenenlerin ne olduğunu somut olarak anlar.

Çağdaş denetim, öğretme ve öğrenmenin geliştirilmesini amaçlayan sürecin temel bir öğesi olarak, verimli çalışma ilişkilerine gereksinim olduğunu vurgular. Çağdaş denetim, öğretimi geliştirmek için denetçilerin ve öğretmenlerin işbirliği yapmaları gerektiğini belirtir (Ovando, 2000). İşbirliği, birden fazla kişi ya da kurumun karşılıklı bazı anlaşmalar yaparak, ayrı programlarla bu programın başarısını artırmak için birlikte çalışmaya karar vermeleridir (Seçkin, 1987). İşbirlikli kavramı, entelektüel çaba içinde başkaları ile birlikte çalışmak anlamına gelir. Daha özel anlamda, öğretimsel kararlara eşit katılım olarak tanımlanır (Ovando, 2000).

İşbirlikli denetim, entelektüel bir çaba içinde başkalarıyla ortaklaşa çalışma olarak tanımlanır (Glickman, 1990). Bir başka tanıma göre, işbirlikli denetim, öğretimsel amaçları başarmak için farklı uzmanlardan oluşan (öğretmen, müdür, denetçi) insanların eşit statüde ve paylaşılmış sorumluluk içinde birlikte çalışma süreci olarak tanımlanır. Bu tanım, denetçiöğretmen etkileşimini, problem çözmeyi, karşıllklı güveni vurgular ve geribildirimlerin değerlendirici ve yargılayıcı olmadığını belirtir (Ovando, 2000). İşbirlikli denetimde denetçinin rolü yönlendirmeden öğretmenlerle birlikte çalışmaktır. Denetçi, karara öğretmenle birlikte aktif olarak katılır (Gebhard, 1984). İşbirlikli denetim, eşitliğe dayanır, bir grup olarak problem çözmeyi amaçlar ve bu süreçte anlaşmazlıklar teşvik edilir, bireylerden görüşlerin kabul edilmesi beklenmez (Shautz, 1995).

Glickman’a (1990) göre işbirlikli denetim yaklaşımında denetçi, problemi öğretmenle eşit olarak paylaşarak çözmeyi arzular. Denetçi, öğretmenin algılarını ve fikirlerini sunması yönünde cesaretlendirir, açıkça bakış açılarını ifade eder ve samimi bir fikir alış-veriş süreci gelişir. Her iki katılımcı herhangi bir eylem hakkında anlaşmaya varacaklarını bilir. Anlaşmazlık olduğunda denetçi, anlaşmazlığı tekrar ifade etmeli ve karşılıklı çözüm bulacaklarını belirtmelidir. Anlaşmazlık teşvik edilmeli, bastırılmamalıdır. Sonuç olarak, denetçi ve öğretmen ya bir eylem hakkında anlaşacaklar ya da anlaşamadıkları sonucuna ulaşacaklardır. Anlaşmazlık durumunda, ileri düzeyde görüşme, yeniden düşünme ve hatta bir arabulucu ya da hakem yoluna başvuracaklardır. Denetçi ve öğretmen arasında görüşme, birbirlerinin problemi nasıl tanımladıklarını anlama ile başlar, son plan üzerinde karşılıklı anlaşma ile son bulur.

Yönlendirici olmayan denetim, yapılması gerekli öğretimsel değişikliklerin neler olduğunu en iyi öğretmenin bildiği, bu yönde düşünme ve eylem yeteneğine sahip olduğu varsayımına dayanır. Bu süreçte öğretimsel kararları öğretmen verir. Denetçinin rolü, öğretmenin düşünme sürecinde ona yardım etmektir. Denetçi, öğretmenin problemi tanımlamaya ve çözmeye odaklı düşüncesini korumaya yönelik davranır (Glickman, 1990; Glickman, Gordon ve Ross-Gordon, 2004).

Örgütlerde kontrol odağının denetçi davranışlarına etkisini belirlemeye yönelik araştırmalar genellikle eğitim örgütleri dışında yapılmıştır. Eğitim örgütlerinde, denetçilerin hangi denetim stilini tercih ettikleri ve bu tercihlerinin kontrol odağından etkilenip etkilenmediğinin belirlenmesi, denetim sürecinin etkililiğine katkı sağlayabilir. Bu çalışmanın amacı, Eğitim 
müfettişlerinin tercih ettikleri denetim stillerinin kontrol odağına göre farklllık gösterip göstermeğini belirlemektir.

\section{Yöntem}

\section{Çalışma grubu}

Çalışmaya 2011-2010 eğitim-öğretim yılında Adana, Batman, Diyarbakır, Erzincan, Eskişehir, Gaziantep, Hatay, Kayseri, Kocaeli, Konya, Mersin, Nevşehir, Niğde, Samsun, Şanlıurfa illerinde çalışan ve 22 Kasım-31 Aralık tarihleri arasında Erzurum'da müfettiş yardımcılarına yönelik hizmet içi eğitim programına katılan 472 eğitim müfettişi ve eğitim müfettiş yardımcısı katılmıştır.

Eğitim müfettişlerinin ve müfettiş yardımcılarının \%4,7'si kadın, \%95,3’ü erkek; \%3’ü eğitim enstitüsü, \%2,1'i önlisans, \%75,2'si lisans ve \%19,7'si lisansüstü mezunu; \%1,3’ü 6-10 yıl, \%19'u 11-15 yll, \%19,5'i 16-20 yll ve \%60,2'si 20 yll ve üzeri memuriyet kıdemine; \%23,9'u 1-5 yll, $\% 15,3$ 'ü 6-10 yll, \%25,4’ü 11-15 yll, \%20,6’sı $16-20$ yll ve $\% 14,8$ 'i 20 yll ve üzeri müfettişlik kıdemine sahiptir.

\section{Veri toplama araçları}

$\mathrm{Bu}$ araştırmada iki farklı ölçme aracı kullanılmıştır. Eğitim müfettişlerinin denetim tercihlerini belirlemek için Glickman (1990) tarafından geliştirilen denetim inançları envanteri, denetim odağını belirlemek için Rotter (1966) tarafından geliştirilen iç-dış kontrol odağı ölçeği kullanılmıştır.

$\mathrm{Bu}$ araştırmada kullanılan denetim inançları envanteri Glickman (1990) tarafından geliştirilmiş, Çetinkanat ve Sağnak (2010) tarafından Türkçeye uyarlanmıştır. Test tekrar test güvenirlik katsayıları yönlendirici denetim inancı .68; işbirlikli denetim inancı .64; yönlendirici olmayan denetim inanc1 .65 olarak bulunmuş ve .01 düzeyinde anlamlı olduğu görülmüştür. Envanter, 15 maddeden oluşan bir araçtır. Her madde zorunlu seçmeli türünde iki seçenekten oluşmaktadır ve 30 seçeneğin 10 'u yönlendirici, 10 'u işbirlikli ve 10 'u yönlendirici olmayan denetim inancını betimlemektedir. Puanlama anahtarına göre her bir seçenek üç alandan birinde yer almaktadır. Tercih edilen seçenek 1, diğeri 0 olarak puanlanmıştır (Clarke ve Collins, 2004).

Rotter (1966) tarafından geliştirilen iç-dış kontrol odağı ölçeğinin geçerlik ve güvenirlik çalışması Dağ (1991) tarafından yapılmıştır. Test tekrar test güvenirlik korelasyon katsayısı .83 , KR-20 tekniği ile hesaplanan güvenirlik katsayısı .68, Cronbach alfa katsayısı .71 olarak bulunmuştur. İç-dış kontrol odağı ölçeği 29 maddeden oluşmakta ve bireylerin genellenmiş kontrol beklentilerinin, içsellik-dışsallık boyutu üzerindeki konumunu saptamayı amaçlamaktadır. Her madde, zorlanmış tercih türünde ikişer seçeneği kapsamaktadır. Altı madde ölçeğin amacını gizlemek için dolgu olarak yerleştirilmiş ve diğer 23 maddenin dişsallık yönündeki seçenekleri l'er puanla değerlendirilmektedir. Ölçek puanları 0 ile 23 arasında değişmekte ve yükselen puan dış kontrol odağı inancının artmasını göstermektedir (Dağ, 1991). Bu araştırmada grup, kontrol 
odağı ortalama puanından ( $\overline{\mathrm{X}}=8,97)$ yüksek olanlar dişsal kontrol odaklı, düşük olanlar içsel kontrol odaklı olarak ikiye bölünmüştür (Cheng, 1994).

Elde edilen veriler araştırmanın amacına uygun olarak aritmetik ortalama, standart sapma ve bağımsız t testi istatistiksel yöntemleri kullanılarak analiz edilmiştir.

\section{Bulgular}

Tablo 1'de, eğitim müfettişlerinin denetim stillerine ilişkin tercihleri ile ilgili betimsel istatistikler yer almaktadır.

Tablo 1

Eğitim Müfettişlerinin Denetim Stillerine Illişkin Tercihleri Ile Illgili Aritmetik Ortalama ve Standart Sapma Dağılımları

\begin{tabular}{|l|c|c|c|}
\hline Denetim Stilleri & $\mathbf{N}$ & $\overline{\mathbf{X}}$ & Ss \\
\hline Yönlendirici & 472 & 4,58 & 1,49 \\
\hline İşbirlikli & 472 & 4,35 & 1,40 \\
\hline Yönlendirici olmayan & 472 & 6,06 & 1,63 \\
\hline
\end{tabular}

Tablo 1'de, eğitim müfettişlerinin denetim stillerine ilişkin tercihleri incelendiğinde; yönlendirici denetim stili $\overline{\mathrm{X}}=4,58$, işbirlikli denetim stili $\overline{\mathrm{X}}=4,35$, yönlendirici olmayan denetim stili $\overline{\mathrm{X}}=6,06$ bulunmuştur. Eğitim müfettişlerinin en yüksek tercihinin yönlendirici olmayan denetim stili ve en düşük tercihinin işbirlikli denetim stili olduğu görülmektedir.

Tablo 2

Kontrol Odağına Göre Eğitim Müfettişlerinin Denetim Stillerine Illişkin Tercihleri Arasındaki Fark lçin t- Testi

\begin{tabular}{|c|c|c|c|c|c|c|c|}
\hline Denetim Stilleri & Kontrol odağı & $\mathbf{N}$ & $\overline{\mathrm{X}}$ & Ss & sd & $\mathbf{t}$ & $\mathbf{p}$ \\
\hline \multirow{2}{*}{ Yönlendirici } & İç & 216 & 4,37 & 1,47 & \multirow{2}{*}{470} & \multirow{2}{*}{2,79} & \multirow{2}{*}{,005 } \\
\hline & Diş & 256 & 4,75 & 1,49 & & & \\
\hline \multirow{2}{*}{ İşbirlikli } & İç & 216 & 4,26 & 1,36 & \multirow{2}{*}{470} & \multirow{2}{*}{1,33} & \multirow{2}{*}{, 182 } \\
\hline & Diș & 256 & 4,43 & 1,43 & & & \\
\hline \multirow{2}{*}{ Yönlendirici olmayan } & İç & 216 & 6,36 & 1,63 & \multirow{2}{*}{470} & \multirow{2}{*}{3,76} & \multirow{2}{*}{, 000} \\
\hline & Diş & 256 & 5,80 & 1,58 & & & \\
\hline
\end{tabular}


Tablo 2'de görüldüğü gibi, kontrol odağı değişkenine göre eğitim müfettişlerinin yönlendirici ve yönlendirici olmayan denetim stillerine ilişkin tercihleri arasında anlamlı fark bulunmuştur. Dış kontrollü eğitim müfettişlerinin yönlendirici denetim stilini, iç kontrollü eğitim müfettişlerinin yönlendirici olmayan denetim stilini daha çok tercih ettikleri belirlenmiştir. Kontrol odağına göre eğitim müfettişlerinin İşbirlikli denetim stiline ilişkin tercihleri arasında anlamlı fark bulunmamıştır.

\section{Tartışma}

Eğitim müfettişlerinin denetim stillerine ilişkin tercihlerinin sırasıyla yönlendirici olmayan denetim, işbirlikli denetim ve yönlendirici denetim olduğu sonucuna ulaşılmıştır. Yönlendirici olmayan denetim yaklaşımı, öğretmenlerin, öğretimsel değişikliklerin ne olduğunu bilme ve bunları gerçekleştirme yeterliğine sahip olduğu anlayışına dayanır. Öğretimsel karar yetkisinin öğretmende olduğu bu yaklaşımda müfettişin rolü, problemi tanımlama ve çözmeye odaklı düşünme sürecinde öğretmene yardım etmektir. Buna göre, eğitim müfettişlerinin öğretimsel kararlarda kontrolün öğretmenlerde olması gerektiği inancına daha çok sahip olduğu söylenebilir.

Blumberg ve Weber (1968); denetçilerin, yönlendirici davranışlarının düşük, yönlendirici olmayan davranışlarının yüksek olduğu davranış stilinde, öğretmenlerin morallerinin en yüksek düzeyde olduğunu belirlemişlerdir. Blumberg (1980), denetçilerin davranış stilinin yönlendirici olduğunda, öğretmenlerin daha çok savunucu olduğu, denetçilerin yönlendirici olmayan stilinin destekleyici iletişime yol açtığı ve etkileşimin verimli olduğu sonucuna ulaşmıştır. Bu bilgilerden yola çıkarak, eğitim müfettişlerinin yönlendirici olmayan denetim inancına sahip olmasının, denetçi-öğretmen arasında sağlıklı iletişim ve etkileşimin gelişmesine yol açacağı söylenebilir.

Öğretmenlerin denetim stillerini belirlemeye yönelik araştırmalar, öğretmenlerin tercihlerini sırasıyla yönlendirici olmayan, işbirlikli ve yönlendirici olduğunu belirlemiştir (Clarke ve Collins, 2004, Çetinkanat ve Sağnak, 2010). Buna göre, eğitim müfettişlerinin denetim stillerine ilişkin tercih sıralamasının öğretmenlerin tercih sıralamasıyla benzerlik gösterdiği söylenebilir. Bununla birlikte, ülkemizde denetim alanında yapılan çalışmalarda; ilköğretim müfettişlerinin uygulamadaki faaliyetleri ile modern teftiş anlayışının öngördüğü faaliyetler arasında fark olduğu; müfettişler ile öğretmenler arasında iletişim yetersizliği görüldüğü, ilköğretim müfettişlerinin öğretmenlere yeterince yardımcı olmadıklarıve öğretmenlerin problemlerini çözmelerinde gerekli çabayı göstermedikleri belirlenmiştir (Burgaz, 1995; Karagözoğlu, 1977; Öz, 1977). Buna göre, bu araştırmada ulaşılan sonuçlar iki şekilde yorumlanabilir. İlki, eğitim müfettişlerinin denetim anlayışı, ast-üst ilişkisine dayalı geleneksel denetim anlayışından işbirlikli yaklaşıma dayalı çağdaş denetim anlayışına doğru bir değişiklik gösterdiği söylenebilir. İkincisi, eğitim müfettişlerinin denetim inançlarıyla denetimsel davranışları arasında farklılıkların olduğu, bununda yönetmelik hükümlerinin müfettişlere yüklediği görevler ve rollerden kaynaklanabileceği ileri sürülebilir. Aydın (1993), Türk eğitim sisteminde, denetim hizmetlerinin yürütülmesinde esas olan yönetmelik ve yönerge hükümleri özde kontrol edici, sapmalara engel olucu, yetersizlikleri saptayıcı bir nitelik taşıdığını belirtmektedir. Bu duruma göre, denetim sisteminin eğitim müfettişlerinin 
denetim inançlarını uygulamalarına ve öğretmenlerin beklentilerini karşılayabilmelerine olanak sağlayacak şekilde yeniden yapılandırılmasına gereksinim olduğu söylenebilir.

Kontrol odağına göre eğitim müfettişlerinin, yönlendirici ve yönlendirici olmayan denetim stillerine ilişkin tercihleri arasında anlamlı fark bulunmuştur. Dışsal odaklı eğitim müfettişlerinin yönlendirici denetim stilini, içsel odaklı eğitim müfettişlerinin ise yönlendirici olmayan denetim stilini daha çok tercih ettikleri belirlenmiştir. Bu sonuca göre, kontrol odağının, müfettişlerin denetim inançlarında farklılığa yol açan bir değişken olduğu söylenebilir.

Goodstadt ve Hjelle (1973), bir denetimsel rol ortamında, dış kontrollü kişilerin daha çok zorlayıcı gücü kullandıklarını, içsellerin daha çok kişisel ikna gücünü kullandıklarını belirlemiştir. Mitchell, Smyser ve Weed (1975), içsellerin katılımcı yönetim stilinden, dışsalların ise yönlendirici stilden daha çok doyum elde ettiklerini, içsellerin astları etkilemede en etkili yollar olarak ödül, uzmanlık ve saygıyı, dışsalların ise formal pozisyonlarını ve zorlayıcı gücü en etkili yollar olarak gördüklerini bulmuştur. Araştırmacılar bu bulgulara dayalı olarak, içsellerin yönetimde daha çok zorlayıcı olmayan bir tarzda davranacaklarını ileri sürmüştür. Rucker ve King (1985), üniversite öğrencileri üzerinde yaptığı araştırmada, içsellerin katılım olanaklarından etkilendiğini, dışsalların yönlendirmeyi tercih ettiğini belirtmiştir. Johnson, Luthans ve Hennessey (1984), içsel denetçilerin dışsallara göre daha çok ikna yolunu kullanma eğiliminde olduklarını belirlemiştir. Bu araştırmada, içsel denetçilerin astları etkilemede daha çok kişisel gücü, dışsal denetçilerin ise kurumsal gücü tercih ettikleri saptanmıştır (Askanasy, 1991).

$\mathrm{Bu}$ araştırmada ulaşılan sonuç, yukarıdaki araştırma sonuçlarıyla paralellik göstermektedir. Dışsal kontrol odaklı eğitim müfettişlerinin içsellere göre, yönlendirici denetim inancına daha çok sahip olduğu sonucuna ulaşılmıştır. Yönlendirici denetim, denetçinin öğretmenden daha çok bilgi ve tecrübeye sahip olduğu varsayımına dayanır. Başka bir deyişle, yönlendirici kontrol davranışları, öğretimin geliştirilebilmesi için neyin yapılması gerektiğini denetçinin öğretmenden daha iyi bildiği inancına dayanır. Bu yaklaşımda denetçi, öğretmene ne yapması gerektiğini söyler ve beklentilerinin yerine getirilip getirilmediğini izler. İçsel kontrol odaklı eğitim müfettişlerinin ise dışsallara göre, yönlendirici olmayan denetim inancına daha çok sahip olduğu sonucuna ulaşılmıştır. Yönlendirici olmayan denetim anlayışı, öğretmenin öğretimsel problemleri tanımlama, çözüm üretme ve uygulama yeterliğine sahip olduğu anlayışına dayalı bir yaklaşımdir.

$\mathrm{Bu}$ araştırma, eğitim müfettişlerinin denetim stillerine ilişkin tercihlerini kontrol odağına göre karşılaştırmayı amaçlamıştır. Glickman (1990), denetim stillerinin okulların yapılanma derecesine, öğretmenlerin yeterlik ve motivasyon düzeylerine göre farklılık gösterebileceğine ileri sürmüştür. Bu değişkenlerin, eğitim müfettişlerinin ve öğretmenlerin denetim stillerine ilişkin tercihlerini etkileyip etkilemediği konusunda bir çalışma yapılabilir. Eğitim örgütlerinde, kontrol odağının okul liderlerinin davranışlarına ve öğretmenlerin bu davranışlara ilişkin algılarına ve tutumlarına yönelik etkileri araştırılabilir. 


\section{Kaynaklar}

Anderson, A., Hattie, J., \& Hamilton, R. J. (2005). Locus of control, self-efficacy, and motivation in different schools: Is moderation the key to success? Educational Psychology, 25(5), 517-535.

Anderson, C. R., \& Schneier, G. E. (1978). Locus of control, leader behavior and leader performance among management student. Academy of Management Journal, 21, 690-698.

Askanasy, N. M. (1991). Supervisors' responses to subordinate performance: Effect of personal-control orientation and situational control. The Journal of Social Psychology, 131(4), 525-544.

Autry, L. B., \& Langenbach, M. (1985). Locus of control and self-responsibility for behavior. Journal of Educational Research, 79(2), 76-84.

Aydın, M. (1993). Çağdaş eğitim denetimi. Ankara: PegemA Yayıncılık.

Biondo, J., \& MacDonald, A. P. (1971). Internal-external locus of control and response to influence attempts. Journal of Personality, 39(3), 407-419.

Blau, G. (1993). Testing the relationship of locus of control to different performance dimensions. Journal of Occupational and Organizational Psychology, 66, 125-138.

Blumberg, A. (1980). Supervisors \& teachers: A private cold war. California: McCutchan Publishing Corporation.

Blumberg, A., \& Weber, W. A. (1968). Teacher morale as a function of perceived supervisor behavioral style. Journal of Educational Research, 62(3), 109-113.

Burgaz, B. (1995). İlköğretim kurumlarının denetiminde yeterince yerine getirilmediği görülen bazı denetim rolleri ve nedenleri. Hacettepe Üniversitesi Eğitim Fakültesi Dergisi, 11, 127-134.

Chen, J-C., \& Silverthorne, C. (2008). The impact of locus of control on job stress, job performance and job satisfaction in Taiwan. Leadership \& Organization Development Journal, 29(7), 572-582.

Cheng, Y. C. (1994). Locus of control as an indicator of Hong Kong teachers' job attitudes and perceptions of organizational characteristics. Journal of Educational Research, 87(3), 180-188.

Clarke, A., \& Collins, J. B. (2004). Glickman's supervisory belief inventory: A cautionary note. Journal of Curriculum and Supervision, 20(1), 76-87.

Çetinkanat, C. \& Sağnak, M. (2010). İlköğretim okullarında görevli öğretmenlerin denetim stillerine ilişkin tercihleri. 2. Uluslararası Katılımlı Eğitim Denetimi Kongresinde Sunulan Bildiri, Dumlupınar Üniversitesi, Kütahya. Bildiriler Kitabı, 85-93.

Dağ, İ. (1991). Rotter’in İç-Dış Kontrol Odağı Ölçeği (RIDDKÖ) nin üniversite öğrencileri için güvenirliği ve geçerliği. Psikoloji Dergisi, 7(26), 10-16.

Deniz, M. E., Traş, Z., \& Aydoğan, D. (2009). Akademik erteleme ve denetim odağının duygusal zeka açısından incelenmesi. Kuram ve Uygulamada Eğitim Bilimleri, 9(2), 607-632.

Durand, D. E., \& Nord, W. R. (1976). Perceived leader behavior as a function of personality characteristics of supervisors and subordinates. Academy of Management Journal, 19, 427-438.

Gebhard, J. G. (1984). Models of supervision: Choices. TESOL Quarterly, 18(3), 501-514.

Glickman, C. D. (1990). Supervision of instruction: A developmental approach. Boston: Allyn and Bacon.

Glickman, C. D., Gordon, S. P., \& Ross-Gordon, J. M. (2004). Supervision and instructional leadership: A developmental approach. New York: Pearson Education, Inc.

Goodstadt, B. E. \& Hjelle, L. A. (1973). Power to powerless: Locus of control and the use of power. Journal of Personality and Social Psychology, 27(2), 190-196.

Johnson, A. L., Luthans, F., \& Hennessey, H. W. (1984). The role of locus of control in leader influence behavior. Personnel Psychology, 37, 61-75.

Karagözoğlu, G. (1977). İlköğretimde teftiş uygulamaları. (Yayınlanmamış araştırma), Ankara. 
Kirkcaldy, B. D., Shephard, R. J., \& Furnham, A. F. (2002). The influence of type A behavior and locus of control upon job satisfaction and occupational health. Personality and Individual Differences, 33, 1361-1371.

Klein, J., \& Wasserstein-Warnet, M. (2000). Predictive validity of the locus of control test in selection of school administrators. Journal of Educational Administration, 38(1), 7-24.

Martin, R., Thomas, G., Charles, K., Epitropaki, O., \& McNamara, R. (2005). The role of leader-member exchanges in mediating the relationship between locus of control and work reactions. Journal of Occupational and Organizational Psychology, 78, 141-147.

Mitchell, T. R., Smyser, C. M., \& Weed, S. E. (1975). Locus of control: Supervision and work satisfaction. Academy of Management Journal, 18(3), 623-631.

Nystrom, P. C. (1982). Managers' personalities and their leadership perceptions. Social Behavior and Personality, 10(2), 189-195.

Ovando, M. N. (2000). Collaborative supervision: Implications for supervision research and inquiry. In J. Glanz \& L. Behar-Horenstein (Eds.), Paradigm debates in curriculum and supervision. Modern and postmodern perspectives. (pp.108-125). Westport: Greenwood Publishing Inc.

Öz, F. (1977). Türk eğitim sisteminde ilköğretim müfettişlerinin rolü. (Yayımlanmamış doktora tezi). Hacettepe Üniversitesi, Ankara.

Parkay, F. W., Greenwood, G., Olejnik, S., \& Proller, N. (1988). A study of the relationships among teacher efficacy, locus of control, and stress. Journal of Research and Development in Education, 21(4), 13 22.

Robbins, S. P. (1986). Organizational behavior: Concepts, controversies, and applications. New Jersey: Prentice-Hall.

Rotter, J. B. (1966). Generalized expectancies for internal versus external control of reinforcement. Psychological Monographs, 80, 1-28.

Rotter, J. B. (1990). Internal versus external control of reinforcement. A case history of a variable. American Psychologist, 45(4), 489-493.

Rucker, M. H., \& King, D. C. (1985). Reactions to leadership style as a function of locus of control and ascendancy of subordinates. Social Behavior and Personality, 13(1), 91-107.

Seçkin, N. (1987). Teftişte yeni gelişmeler. Çağdaş Eğitim, 121, 12-17.

Shautz, D. (1995). Women supervisors have a greater understanding of what take place in classrooms than men. Education, 116(2), 210-214.

Spector, P. E. (1982). Behavior in organizations as a function of employee's locus of control. Psychological Bulletin, 91(3), 482-497.

Türker, M. V., \& İnel, M. N. (2012). The effect of locus of control orientation on perceived individual innovativeness: An empirical research in Turkey. Procedia-Social and Behavioral Sciences, 58, 879888. 